Çukurova Üniversitesi Mühendislik Mimarlık Fakültesi Dergisi, 34(4), ss. 147-161, Aralık 2019

\title{
Kurumsal Sürdürülebilirlik Performans Analizinde CRITIC-EDAS Yaklaşımı
}

\author{
Neşe YALÇIN ${ }^{1}$, Esra KARAKAŞ ${ }^{* 2}$ \\ ${ }^{1}$ Adana, Aplarslan Türkeş Bilim ve Teknoloji Üniversitesi, Mühendislik Fakültesi, Endüstri \\ Mühendisliği Bölümü, Adana \\ ${ }^{2}$ Adana, Aplarslan Türkeş Bilim ve Teknoloji Üniversitesi, İşletme Fakültesi, İşletme Bölümü,
} Adana

Geliş tarihi: 12.11.2019 Kabul tarihi: 20.12.2019

\section{$\ddot{\mathbf{O} z}$}

Ülke ekonomisindeki rolleri ve stratejik önemleri nedeniyle enerji sektöründeki şirketler sadece ekonomik değerlerini artırmaya değil aynı zamanda kurumsal sürdürülebilirliklerini bütün boyutları ile geliştirmeye de odaklanmalıdır. Bu çalışmada, kurumsal sürdürülebilirlik performans değerlendirmesi için CRITIC ve EDAS yöntemlerinin entegre edildiği bütünleşik bir yaklaşım önerilmiştir. Önerilen yöntemle bir enerji firmasının 2010-2018 yılları itibariyle kurumsal sürdürülebilirlik performansı değerlendirilmiștir. Sürdürülebilirlik kriterlerinin ağırlıklarının hesaplanmasında kriterlerin gerçek değerinin kullanılmasına dayanan objektif ağırlıklandırma yöntemlerinden biri olan CRITIC yöntemi kullanılmıştır. Hesaplanan kriter ağırlıkları girdi olarak EDAS yönteminde kullanılmış ve firmanın yıllar itibariyle kurumsal sürdürülebilirlik değerlendirmesi gerçekleştirilmiștir. Analiz sonuçlarına göre, firmanın kurumsal sürdürülebilirlik performansının istikrarlı bir durum sergilemediği ancak 2018 y1lı itibariyle tekrar yükselişe geçtiği görülmüştür. Ayrıca, farklı kriter ağırlıklandırma yöntemleriyle EDAS yöntemi entegre edilerek elde edilen sonuçlar kıyaslanmıştır. Mevcut yaklaşımın, kurumsal sürdürülebilirlik performansının değerlendirilmesinde uygun bir araç olduğu ortaya konmuştur.

Anahtar Kelimeler: Kurumsal sürdürülebilirlik, Enerji firmaları, ÇKKV, CRITIC, EDAS

\section{CRITIC-EDAS Approach in Corporate Sustainability Performance Analysis}

\begin{abstract}
Because of their role in the national economy and strategic importance, energy firms should focus not only on economic growth, but also on improving their corporate sustainability in all aspects. In this study, an integrated method, which integrates CRITIC and EDAS method, is proposed for corporate sustainability performance evaluation. Using the proposed method, the corporate sustainability performance of an energy company as of 2010-2018 was evaluated. The CRITIC method, one of the objective weighting methods based on the actual value of the criteria, was used to calculate the weights of the sustainability criteria. The calculated criteria weights were used as input in the EDAS method and the corporate sustainability assessment of the company was conducted over the years. According to the
\end{abstract}

"Sorumlu yazar (Corresponding author): Esra KARAKAȘ, ekarakas@atu.edu.tr 
results of the analysis, it is observed that the corporate sustainability performance of the company is not stable but it has started to increase as of 2018. In addition, the results obtained by integrating the EDAS method with different criteria weighting methods were compared. It has been demonstrated that the proposed approach is an appropriate tool for evaluating corporate sustainability performance.

Keywords: Corporate sustainability, Energy firms, MCDM, CRITIC, EDAS

\section{GİRIŞ}

Sanayi devrimi ile birlikte ortaya çıkan endüstriyelleşme, kaynakların hızlı bir şekilde tüketilmesine ek olarak çevre üzerinde de önemli tahribatlar yapmıştır. Bu sonuçlar, özellikle 20 . yüzyılın başlarından itibaren dünya üzerinde çeşitli ülkelerin en önemli gündem maddelerinden biri haline gelmiştir ve mevcut kaynakların gelecek nesillere aktarılmasının, yani sürdürülebilir olmasının gerekliliği fark edilmeye başlanmıştır [1]. Sürdürülebilirlik kavramı ile ilgili ilk tanıma, 1987 yılında Dünya Çevre ve Kalkınma Örgütü (WCED) tarafindan hazırlanan Bruntland Raporu'nda yer verilmiştir. Brutland Raporu'nda sürdürülebilirlik, gelecek nesillerin refahında bir azalma olmaksızın şimdiki neslin ihtiyaçlarının karşılanması olarak tanımlanmıştır [2]. Sürdürülebilirlik kavramının işletmeler açısından karşılığ1 ise kurumsal sürdürülebilirlik olarak karşımıza çıkmaktadır. Kurumsal sürdürülebilirlik, işletmelerin finansal amaçlarına ulaşmak için çaba gösterirken ortaya çıkan ekonomik, çevresel ve sosyal sonuçlardan da sorumlu olması gerektiğini vurgulamaktadır [3] Diğer bir ifadeyle kurumsal sürdürülebilirlik; ekonomik, çevresel ve sosyal gelişmelerden kaynaklanan firsatları değerlendirip yöneterek ve riskleri bertaraf ederek, uzun vadede değer yaratan bir yaklaşımdır. $\mathrm{Bu}$ nedenle kurumsal sürdürülebilirliğin, çevresel, sosyal ve ekonomik olmak üzere üç boyutu vardır [4]. Ekonomik sürdürülebilirlik, işletmenin kar etmesi ve sağlam bir finansal yapıya sahip olması ile gerçekleştirilirken, çevresel sürdürülebilirlik; işletmenin çevreye zarar vermeksizin ya da en az zarar vererek faaliyette bulunması ve doğal kaynakların gelecek nesiller için de korunmasını ifade etmektedir. Sosyal sürdürülebilirlik ise, işletme çalışanlarının çalışma ve yaşam şartlarının iyileştirilmesi, müşterilerinin, yerel toplumun ve gelecek nesillerin hayat kalitesinin göz önünde bulundurulmasını ifade etmektedir [5]. Ekonomik, sosyal ve çevresel sürdürülebilirlik çok sayıda gösterge (kriter) ile ifade edilmekte ve kurumsal sürdürülebilirlik performansının analiz edilmesinde bu göstergeler kullanılmaktadır.

Kurumsal sürdürülebilirlik performansının firma düzeyinde değerlendirilmesi ve uygun yöntemler kullanılarak analiz edilmesi son yıllarda çalışılan konular arasına girmiştir. Konu ile ilgili daha önce yapılmış çalışmalar incelendiğinde, kurumsal sürdürülebilirlik performansının değerlendirilmesi amacıyla çok kriterli karar verme (ÇKKV) yöntemlerinin sıklıkla kullanıldığı görülmüştür. Ekonomik, sosyal ve çevresel sürdürülebilirlik boyutlarının, kendi içerisinde fazla sayıda gösterge ile ifade edilmesi nedeniyle sürdürülebilirlik performansının ölçülmesinde birçok zorlukla karşılaşılmaktadır. ÇKKV, her bir gösterge için gerçek değerleri kullanarak veya uzman görüşleri ile göreli önem değerlerini hesaplayabilmektedir. Diğer bir ifade ile kurumsal sürdürülebilirlik boyutlarına ait göstergeler kurumsal sürdürülebilirlik performans değerlendirmesi probleminin kriterleri olarak kabul edilmektedir. $\mathrm{Bu}$ açıdan ÇKKV yöntemlerinin sürdürülebilirliğin değerlendirilmesinde uygun bir çerçeve sunduğu ortaya konmuş ve sonrasında birçok araştırmacı tarafindan farklı ÇKKV yöntemleri bu amaçla kullanılmıştır. Türkiye'de yapılan çalışmalar incelendiğinde; özellikle kimya, beyaz eşya, enerji vb. sektörler ile bankalar üzerine kurumsal sürdürülebilirlik performans değerlendirmesinin analizinde farklı ÇKKV yöntemlerinin kullanıldığı görülmektedir. Alp ve arkadaşları [6], ÇKKV yöntemlerinden MAUT (Multi-Attribute Utility Theory) ve Entropi yöntemlerini kullanarak kimya sektöründe faaliyet gösteren bir firmanın kurumsal sürdürülebilirlik performansını değerlendirmişlerdir. Öncelikle, kriterlerin önem düzeyleri (ăğrlıkları) Entropi objektif ağırlıklandırma yöntemiyle belirlenmiştir. Yıllar bazında kurumsal 
sürdürülebilirlik performansının analizi ise MAUT yöntemiyle gerçekleştirilmiştir. Çalışmalarında, şirketin yayımladığ 1 2009-2012 dönemlerine ait beş yıllık sürdürülebilirlik raporlarından elde edilen veriler derlenerek kriterler belirlenmiştir. Ergüden ve Çatlıoğlu [7], enerji sektöründe faaliyet gösteren firmaların sürdürülebilirlik performansinı TOPSIS (Techique for order preference by similarity to an ideal solution) yöntemi kullanılarak incelenmiş ve ele alınan dönem itibari ile kurumsal sürdürülebilirlik performansı en iyi olan firmanın Zorlu Enerji olduğunu tespit etmişlerdir. Aras ve arkadaşları [8], Garanti bankasının kurumsal sürdürülebilirlik performans değerlendirmesinde içerik analizi ile Entropi tabanlı TOPSIS yöntemini kullanmışlardır. Bankanın 2010-2014 döneminde yayımlanan sürdürülebilirlik raporları, içerik analizi ile değerlendirilerek uygun kriterler belirlenmiş ve sonrasında Entropi tabanlı TOPSIS yöntemi ile kurumsal sürdürülebilirlik performans1 değerlendirilmiştir. Elde edilen sonuçlar neticesinde, bankanın kurumsal sürdürülebilirlik performansının yükseliş eğiliminde olduğu ve ayrıca toplam sürdürülebilirlik performansı üzerinde; ekonomik boyutun en yüksek etkiye sahip olduğu tespit edilmiştir. Ömürbek ve arkadaşları [9], aktif büyüklüklerine göre büyük ölçekli banka sınıflandırmasında yer alan yedi bankanın sürdürülebilirlik performanslarını, ENTROPI, ARAS, MOOSRA ve COPRAS gibi yöntemler ile değerlendirerek karşılaştırmışlardır. Bankaların sürdürülebilirlik raporları ve faaliyet raporlarındaki veriler dikkate alınarak, toplamda 13 adet kriter çerçevesinde değerlendirmeler yapılmıştır. Küçükbay ve Sürücü [10], Multimoora Sort adını verdikleri yeni bir ÇKKV metodu önermişler ve Fortune 500 listesinde yer alan 25 firmaya ait kurumsal sürdürülebilirlik analizini önerdikleri yöntem ile gerçekleştirmişlerdir. Belirtilen bu çalışma kapsamında, dört ekonomik ve sosyal, iki de çevresel olmak üzere toplam 10 kriter dikkate almışlardır. Ersoy [11], beyaz eşya sektöründe faaliyet gösteren bir firmanın kurumsal sürdürülebilirlik performansı değerlendirmek için Entropi, Topsis ve Gri İlişkisel Analiz (GİA) yöntemlerinden oluşan bütünleşik bir yaklaşım önermiştir. Kriterlerin ağırlıkları Entropi yöntemi ile hesaplanmış ve sonrasında TOPSIS ve Gri
İlişkisel Analiz yardımıyla yıllar bazında kurumsal sürdürülebilirlik performansı değerlendirilmiştir. Öztel ve arkadaşları [12], Topsis yöntemi ve Entropi yöntemini birlikte kullanılarak Akenerji firmasının kurumsal sürdürülebilirlik performans1 değerlendirmiştir. İncelenen şirketin kurumsal sürdürülebilirlik performansı ekonomik, sosyal ve çevresel boyutlarıyla yıllara göre analiz edilmiştir. Ecer [13], Entropi-ARAS bütünleşik modeli kullanarak Türkiye'deki özel sermayeli bankaların kurumsal sürdürülebilirlik performanslarını analiz etmiş ve sonrasında duyarlılık analizi yapmıştır. Çalışmanın önemli katkılarından birinin, bankaların kurumsal sürdürülebilirlik performanslarında etkili olan kriterlerin ağırlıklarının objektif olarak belirlenmesi olduğu vurgulanmıştır. Çalışmanın bulgularına göre, kurumsal sürdürülebilirlik bakımından yüksek performans hedefine ulaşmayı amaçlayan bankalar, öncelikle personel devir hızlarını düşürmeli, ardından doğrudan sera gazı tüketimini azaltmalıdırlar. Korzeb ve Medina [14], Polonya bankalarının sürdürülebilirlik performansını TOPSIS yöntemini kullanarak değerlendirmişlerdir. Sürdürülebilir alanında daha fazla ÇKKV uygulamalarına dair çalışmalara ulaşmak içim Stojcic ve arkadaşları[15] tarafından gerçekleştirilmiş olan literatür taraması incelenebilir.

$\mathrm{Bu}$ çalışmada, enerji sektöründe yer alan bir firmanın kurumsal performansının yıllar bazında değerlendirilmesinde ÇKKV yöntemleri olarak bilinen CRITIC ve EDAS yöntemlerinin bütünleşik bir yaklaşımla kullanılarak analiz edilmesi amaçlanmıştır. Öncelikle, kurumsal sürdürülebilirlik performans ölçümü yapılacak enerji firmasının seçimi için BISST'de işlem gören firmalar tespit edilmiş ve analiz yapılacak uygun bir firma seçilmiştir. Enerji firmasına ait 20102018 yılları arası sürdürülebilirlik raporları ve faaliyet raporları incelenerek; sosyal, ekonomik ve çevresel sürdürülebilirlik göstergeleri ortaya konmuştur. Kurumsal sürdürülebilirlik kriterlerinin belirlenmesinde, kriterlerin raporlarda yer alması ve ölçülebilir olması dikkate alınmıştır. Sonrasında, kriterlerin ağırlıkları CRITIC yöntemi ile hesaplanmış ve EDAS yönteminin girdileri olarak kullanılmıştır. EDAS yönteminden elde 
edilen veriler, firmanın ele alınan yıllar içerisinde sürdürülebilirliğin her üç boyutundaki durumunu ortaya koymuştur. Ayrıca, çalışmada farklı objektif ağırlıklandırma yöntemlerinin elde edilen sonuçlar üzerindeki etkisini görebilmek amacıyla, sürdürülebilirlik boyutlarına ait kriterlerin ağırlıkları belirlenmiştir. Farklı yöntemlerden elde edilen ağırlıklar aynı şekilde EDAS yönteminin girdisi olarak kullanılmıştır. Böylece, farklı ağırlıklandırma yöntemlerinden oluşan bütünleşik yaklaşımlara göre yıllar bazındaki performans skorları elde edilmiş ve elde edilen sonuçların kıyaslaması yapılmıştır.

\section{METOT}

Bu bölümde, çalışmada enerji firmasının kurumsal sürdürülebilirlik performans değerlendirmesi amaciyla önerilen CRITIC-EDAS bütünleşik yaklaşımını içeren ÇKKV yöntemlerinin alt başlıklarda detaylı bir şekilde açıklaması yapılmıştır.

\subsection{CRITIC Yöntemi}

ÇKKV probleminde çok sayıda çelişen özellikteki kriterlerin ağırlıkları problemin sonucu üzerinde çok önemli olup, kriter ağırlıklarının hem sübjektif hem de objektif ağırlıklandırma yöntemleri kullanılarak belirlenmesi söz konusudur. ÇKKV'de kriter ağırlıklarının belirlenmesi üç şekilde yapılabilmektedir. Bunlar; uzman temeline dayanan sübjektif ağırlıklandırma yöntemleri, veri temeline dayalı olan objektif ağırlıklandırma yöntemleri ve her iki yöntemin birleştirilmesiyle elde edilen entegre ağırlıklandırma yöntemleri şeklindedir [16]. Literatürde yaygın kullanılan objektif ağırlıklandırma yöntemlerinden bazıları şunlardır: entropi yöntemi [17], kriterler arası korelasyon (CRITIC) yöntemi [18], standart sapma metodu [17,18], maksimize sapma metodu [19] ve Ma ve arkadaşları tarafından geliştirilen objektif yaklaşım yöntemi [20].

Bu çalışmada, kurumsal performans boyutlarına ait kriterlerin ağırlıklarının elde edilmesinde yıllar bazındaki verilerden yararlanıldığından, bir objektif ağırlıklandırma yöntemi olan Diakoulaki ve arkadaşları [18] tarafından geliştirilen CRITIC yöntemi uygulanmıştır. Bu yöntem, ağırlıkları hesaplarken, kriterlerin gerçek verilerini içeren karar matrisinden faydalanmaktadır. Her bir kriterin standart sapması ve kriterler arası korelasyon değerleri, objektif ağırlıkların belirlenmesinde dikkate alınan değerlerdir. Bu yöntemden elde edilen kriter ağırlıkları alternatiflerin (yılların) nihai sıralaması için kullanılan EDAS yönteminin girdilerini oluşturmaktadır.

CRITIC yönteminin adımları sırasıyla şu şekilde açıklanabilir [18]:

Adım 1: Karar matrisinin oluşturulması.

Eşitlik 1 ile ifade edilen karar matrisinde; $i$ indisi alternatifleri, $j$ indisi ise kriterleri temsil etmektedir. $\mathrm{x}^{\mathrm{ij}}, i$. alternatifin $j$. kriter bakımından performans değerini ifade etmektedir.

$$
\begin{aligned}
& \begin{array}{llll}
C_{1} & C_{2} & \cdots & C_{n}
\end{array} \\
& X=\left[X_{i j}\right]_{m \times n}=\begin{array}{c}
A_{1} \\
= \\
A_{2} \\
A_{m}
\end{array}\left[\begin{array}{cccc}
x_{11} & x_{12} & \cdots & x_{1 n} \\
x_{21} & x_{22} & \cdots & x_{2 n} \\
\vdots & \vdots & \ddots & \vdots \\
x_{m 1} & x_{m 2} & \cdots & x_{m n}
\end{array}\right]
\end{aligned}
$$

Adım 2. Karar matrisinin normalize edilmesi.

Eşitliklerden fayda kriterleri için Eşitlik 2, maliyet kriterleri için Eşitlik 3 kullanılır. Bu durumda, karar matrisinin elemanları $\mathrm{x}_{\mathrm{ij}}$ 'den, normalize edilmiş değerler olan $r_{i j}$ 'ye dönüştürülmüş olur.

$$
\begin{aligned}
& r_{i j}=\frac{x_{i j}-x_{j}^{\min }}{x_{j}^{\max }-x_{j}^{\min }} \\
& r_{i j}=\frac{x_{j}^{\max }-x_{i j}}{x_{j}^{\max }-x_{j}^{\min }}
\end{aligned}
$$

$x_{j}^{\max }: j$. kriterin alternatifler arasındaki en yüksek değeri

$x_{j}^{\min }: j$. kriterin alternatifler arasındaki en düşük değeri 
Adım 3. Kriter çiftleri için korelasyonun hesaplanması. Eşitlik 4 ile gerçekleştirilir.

$$
\rho_{j k}=\frac{\sum_{i=1}^{m}\left(r_{i j}-\bar{r}_{j}\right)\left(r_{i k}-\bar{r}_{k}\right)}{\sqrt{\sum_{i=1}^{m}\left(r_{i j}-\bar{r}_{j}\right)^{2} \sum_{i=1}^{m}\left(r_{i k}-\bar{r}_{k}\right)^{2}}}
$$

$\rho_{j k}, j$. ve $k$. kriterler arasındaki korelasyon katsayısıdır.

Adım 4. Kriter ağırlıklarının hesaplanması. Eşitlik 5-7 ile gerçekleştirilir.

$\sigma_{j}=\sqrt{\frac{\sum_{i=1}^{m}\left(r_{i j}-\bar{r}_{j}\right)^{2}}{m}}$

$c_{j}=\sigma_{j} \sum_{k=1}^{n}\left(1-\rho_{j k}\right)$

$w_{j}=c_{j} / \sum_{k=1}^{n} c_{k}$

$j=1,2, \ldots, n$ için, $\sigma_{j}: j$. kriterin standart sapma değeri, $w_{j}: j$. kriterin ağırlığını ifade eder.

\subsection{EDAS Yöntemi}

$\mathrm{Bu}$ çalışmada, Ghorabaee ve arkadaşları [21] tarafından geliştirilen EDAS (Evaluation based on Distance from Average Solution-Ortalama Çözüm Uzaklığına Göre Değerlendirme) yöntemi kullanılmıştır. EDAS yöntemi, uzaklığa bağlı çözüm bulmaya çalışan bir ÇKKV yöntemdir. $\mathrm{Bu}$ yöntemde, alternatifler değerlendirilirken ideal çözümden olan uzaklık yerine ortalama çözümden olan uzaklık dikkate alınır. Bu yöntemde en iyi alternatif, alternatiflerin her bir kritere göre ortalama çözüm (average solution- $A V_{j}$ ) uzaklıkları hesaplanarak bulunur. Alternatiflerin kabul edilebilirliğinde ortalamadan pozitif uzaklık (positive distance from average- $P D A_{i j}$ ) ve ortalamadan negatif uzaklik (negative distance from average- $N D A_{i j}$ ) olmak üzere iki ölçüt kullanılır. Alternatif değerlendirme aşamasında, $P D A_{i j}$ 'nin daha yüksek değerleri ve/veya $N D A_{i j}{ }^{\prime}$ nin daha düşük değerleri, alternatifin ortalama çözümden daha iyi olduğunu ortaya koyar.

Literatürde geliştirilen ÇKKV yöntemleri arasında hemen hemen yeni sayılabilecek EDAS yöntemi ilk olarak Ghorabaee ve arkadaşları [21] tarafindan envanter kalemlerinin ABC sınıflandırmasında kullanılmıştır. Daha sonra bazı farklı alanlardaki çok kriterli karar probleminin çözümünde başarı ile uygulanmıştır. Örneğin; kimyasal malzeme üreten en uygun tedarikçi firma seçiminde [22], en uygun makinenin seçiminde [23], konut seçiminde [24], katı atık bertaraf sahasının belirlenmesinde [25], en uygun üçüncü parti lojistik (3PL) firma seçiminde [26], yerli bir firmanın bilgi teknolojileri sahasında uzman istihdamı için personel seçiminde [27], en uygun konveyör seçiminde [28], otomobillerde dişli ve tampon malzemesi seçiminde [29], lojistik firma web sitelerinin değerlendirilmesinde [30] EDAS yöntemi uygulanmıştır.

EDAS yönteminin adımları sırasıyla şu şekildedir [19]:

Adım 1: $m$ adet alternatif ve $n$ adet kriter dikkate alınarak karar matrisi oluşturulur. Karar matrisinin yapısı Eşitlik 1'de verildiği gibidir.

Adım 2: Tüm ölçütlere göre ortalama çözüm hesaplanır. Ortalama çözümün belirlenmesi için Eşitlik 8 ve 9 kullanılır:

$A V=\left[A V_{j}\right]_{1 x n}$

$$
A V_{j}=\frac{\sum_{i=1}^{m} x_{i j}}{m}
$$

Adım 3: Her kriter için ortalamadan pozitif uzaklık (PDA) ve ortalamadan negatif uzaklık (NDA) matrisleri oluşturulur. Hesaplamalar yapılırken kriterler fayda cinsinden ise Eşitlik 12 ve 13, maliyet cinsinden ise Eşitlik 14 ve 15 kullanılır. 


$$
\begin{aligned}
& P D A=\left[P D A_{i j}\right]_{m x n} \\
& N D A=\left\lfloor N D A_{i j}\right\rfloor_{m x n} \\
& P D A_{i j}=\frac{\max \left(0,\left(x_{i j}-A V_{j}\right)\right)}{A V_{j}}, \\
& N D A_{i j}=\frac{\max \left(0,\left(A V_{j}-x_{i j}\right)\right)}{A V_{j}}, \\
& P D A_{i j}=\frac{\max \left(0,\left(A V_{j}-x_{i j}\right)\right)}{A V_{j}}, \\
& N D A_{i j}=\frac{\max \left(0,\left(x_{i j}-A V_{j}\right)\right)}{A V_{j}}
\end{aligned}
$$

Adım 4: Her bir alternatif için ağırlıklandırılmış toplam PDA ve NDA $\left(S P_{i}\right.$ ve $\left.S N_{i}\right)$ hesaplanır.

$$
\begin{aligned}
& S P_{i}=\sum_{j=1}^{n} w_{j} P D A_{i j} \\
& S N_{i}=\sum_{j=1}^{n} w_{j} N D A_{i j}
\end{aligned}
$$

$w_{j}, j$. kriterin ağırlığını göstermektedir.

Adım 5: Her alternatif için $S P$ ve $S N$ değerleri normalize edilir.

$$
\begin{aligned}
& N S P_{i}=\frac{S P_{i}}{\max _{i}\left(S P_{i}\right)}, \\
& N S N_{i}=1-\frac{S N_{i}}{\max _{i}\left(S N_{i}\right)},
\end{aligned}
$$

Adım 6: Bütün alternatifler için değerlendirme puanı $\left(A S_{i}, 0 \leq A S_{i} \leq 1\right)$ hesaplanır.

$$
A S_{i}=\frac{1}{2}\left(N S P_{i}+N S N_{i}\right)
$$

Adım 7: Alternatifler, hesaplanan değerlendirme puanına $(A S)$ göre azalan düzeyde sıralanır. İlk sıradaki alternatif, en iyi alternatif olarak kabul edilir.

\section{UYGULAMA}

Enerji sektörü, ulusal ekonomilerin büyüklüğü ve gücünü belirleyen önemli sektörlerden biridir. Sektörün ülke ekonomisi üzerindeki etkisi, yalnızca finansal yönden değil sosyal, refah ve çevresel yönleri dikkate alarak dengeli bir yaklaşımla değerlendirilmelidir. Bilindiği üzere, enerji sektörü, madencilik, ticaret, işleme, inşaat ve taşımacılık gibi diğer sanayilerin işleyişinde önemli bir etkiye sahiptir [31]. Ülke ekonomisindeki rolleri ve stratejik önemleri nedeniyle, enerji sektöründeki şirketler sadece ekonomik değerlerini artırmaya değil aynı zamanda kurumsal sürdürülebilirliklerini bütün boyutları ile ele alarak geliştirmeye de odaklanmalıdır. Bu açıdan, yıllar bazında kurumsal sürdürülebilirliklerinin değerlendirilmesi gereklidir.

Mevcut çalışmada, enerji sektörünün stratejik önemi dikkate alınarak, ülkemizde faaliyet gösteren bir enerji firması için kurumsal sürdürülebilirlik değerlendirmesi yapılması amaçlanmıştır. $\mathrm{Bu}$ amaçla, öncelikle değerlendirme yapılacak enerji firmasının belirlenmiş ve sonrasında enerji firmasının sürdürülebilirlik raporlarının detaylı bir şekilde incelenip, her bir sürdürülebilirlik boyutuna ait kriterler ortaya konmuştur.

Uygulama yapılacak enerji firmasının belirlenebilmesi için öncelikle Borsa İstanbul'da (BİST) işlem gören enerji firmaları arasında sürdürülebilirlik raporu yayınlayan firmalar incelenmiştir. Uygulama yapılacak firma belirlenirken, daha uzun yillar boyunca sürdürülebilirlik raporunun mevcut olması ve mevcut raporlar içerisinde yer alan sürdürülebilirlik göstergelerine ait değerlerin 
mümkün olduğunca her yıl tutarlı bir șekilde vermiş olması göz önüne alınmıştır. Kurumsal sürdürülebilirlik performansına ait kriter belirlenirken ise sürdürülebilirlik raporunda verilere ulaşılabilirlik ve uzman görüşleri dikkate alınmıştır. Sürdürülebilirlik kriterleri alt bölümde açıklanmıştır.

\subsection{Kurumsal Sürdürülebilirlik Performans Ölçütlerinin Belirlenmesi}

$\mathrm{Bu}$ çalışmada, BİST'de işlem gören bir enerji firmasının sürdürülebilirlik verileri dikkate alınmıştır. Firma, 2012 yılından bu yana sürdürülebilirlik raporlarını düzenli olarak yayınlayan enerji firmalarından biridir. Firmanın kurumsal sürdürülebilirlik performansının değerlendirilmesi için, çevresel sürdürülebilirlik boyutu (ÇSB), sosyal sürdürülebilirlik boyutu
(SSB) ve ekonomik sürdürülebilirlik boyutu (ESB) alanlarında ilgili kriterlerin belirlenmesi gerekmektedir.

Sosyal ve çevresel boyutlar altında yer alan kriterler, mevcut sürdürülebilirlik raporlarından ulaşılabilirlik esasına göre belirlenmiştir. Ekonomik göstergeler ise, finansman alanındaki uzmanların görüşleri alınarak belirlenmiş ve ilgili verilere firmanın yayımlamış olduğu faaliyet raporlarından ulaşılmıştır. $\mathrm{Bu}$ açıdan mevcut çalışmada ele alınan kriterler, önceki çalışmalar bölümünde de bahsedilmiş olan Öztel ve arkadaşları [12] tarafından yapılan çalışmadan ele alınan kriterler açısından farklılık gösterebilmektedir. $\mathrm{Bu}$ çalışmada kurumsal sürdürülebilirlik performans açısından her bir boyuta ait kriterler Çizelge 1'de verilmiştir.

Çizelge 1. Kurumsal Sürdürülebilirlik Performans Kriterleri

\begin{tabular}{|c|c|c|}
\hline \multicolumn{2}{|l|}{ ÇSB alt boyutları (kriterleri) (ÇSb) } & ESB alt boyutları (kriterleri) (ESb) \\
\hline \multicolumn{2}{|c|}{$\begin{array}{l}\text { ÇSb1: Yakıt tüketimi (gj) } \\
\text { ÇSb2: Elektrik tüketimi (yenilenemez kaynaklı) (GJ) } \\
\text { ÇSb3: Elektrik tüketimi (yenilenebilir kaynaklı) (GJ) } \\
\text { ÇSb4: Toplam su tüketimi }\left(\mathrm{m}^{3}\right) \\
\text { ÇSb5: Atık su }\left(\mathrm{m}^{3}\right) \\
\left.\text { ÇSb6: Toplam sera gazı salınımı (tonCO }{ }_{2}-\mathrm{e}\right) \\
\text { ÇSb7: Geri dönüştürülmüş tehlikesiz atık miktarı }(\mathrm{kg}) \\
\text { ÇSb8: Geri dönüştürülmüş tehlikeli atık miktarı }(\mathrm{kg}) \\
\text { ÇSb9: Toplam geri dönüştürülmüş atık miktarı }(\mathrm{kg})\end{array}$} & $\begin{array}{l}\text { ESb1: Kapanış Fiyatı } \\
\text { ESb2: Piyasa Değeri (Yılsonu Kapanış } \\
\text { Fiyatına Göre) } \\
\text { ESb3: Net Satışlar } \\
\text { ESb4: Faaliyet Karı } \\
\text { ESb5: Net Dönem Karı } \\
\text { ESb6:Toplam Varlıklar } \\
\text { ESb7: Faaliyet Kar Marjı } \\
\text { ESb8:Öz Sermaye Karlılığ1 } \\
\text { ESb9:Varlık Karlılığ1 }\end{array}$ \\
\hline \multicolumn{3}{|c|}{ SSB alt boyutları (kriterleri) (SSb) } \\
\hline $\begin{array}{l}\text { SSb1: Toplam çalışan sayısı } \\
\text { SSb2: Dışardan alınan hizmet kapsamında } \\
\text { çalışan sayısı } \\
\text { SSb3: İşgücü devir hızı oranı } \\
\text { SSb4: Beyaz yaka istihdamı } \\
\text { SSb5: Mavi yaka istihdamı } \\
\text { SSb6: Tüm işgücünde çalışan kadın oranı } \\
\text { SSb7: Orta düzey yönetici pozisyonunda çalışan } \\
\text { kadın oranı }\end{array}$ & & $\begin{array}{l}\text { : Üst düzey yönetici pozisyonunda çalışan } \\
\text { oranı } \\
\text { : Çalışanlara verilen eğitimlerin toplam saati } \\
\text { 0: Çalışan başına yıllık ortalama eğitim saati } \\
\text { 1: Araç kaza sayısı } \\
\text { 2: Toplam araç kaza oranı } \\
\text { 3: İş kazası sıklık hızı (Ak-enerji iştirak } \\
\text { anları) } \\
\text { 4: İş kazası ağırlık hızı (Ak-enerji iştirak } \\
\text { anları) }\end{array}$ \\
\hline
\end{tabular}

Çevresel, sosyal ve ekonomik sürdürülebilirlik boyutlarına ait her bir kriterin değeri sırasıla Çizelge 2, Çizelge 3 ve Çizelge 4'de verilmiştir. Her bir boyutta yer alan alt boyutların performans üzerinde maksimum veya minimum etkisi olup, bu etkiler analizlerde doğru sonuçların elde edilmesi açısından dikkate alınmıştır. ÇSB altında yer alan 2 kriter (ÇSb3 ve ÇSb7) maksimum ve geriye kalan 7 kriter (ÇSb1, ÇSb2, ÇSb4, ÇSb5 ve ÇSb6) minimum etkiye; SSB altında yer alan 9 kriter 
(SSb1, SSb2, SSb4, SSb5, SSb6, SSb7, SSb8, $\mathrm{SSb} 9$ ve SSb10) maksimum ve 5 kriter minimum (SSb3, SSb11, SSb12, SSb13 ve SSb14) etkiye;
ESB altında yer alan tüm kriterler ise maksimum etkiye sahiptir.

Çizelge 2. ÇSB kapsamında yer alan kriterler bakımından 2010-2018 yıllarına ait veri seti

\begin{tabular}{|c|c|c|c|c|c|}
\hline Yllar & ÇSb1 & ÇSb2 & ÇSb3 & ÇSb4 & ÇSb5 \\
\hline 2010 & 32294 & 16163 & 1667 & 1386420 & 130423 \\
\hline 2011 & 360327 & 15488 & 4281 & 1420539 & 123146 \\
\hline 2012 & 325452 & 20027 & 6135 & 1229309 & 123071 \\
\hline 2013 & 122121 & 25348 & 5716 & 444625 & 49216 \\
\hline 2014 & 55278 & 80755 & 2993 & 579134 & 328222 \\
\hline 2015 & 495953 & 103393 & 7966 & 1178165 & 721956 \\
\hline 2016 & 422743 & 115709 & 4805 & 2213942 & 10448738 \\
\hline 2017 & 742431 & 50672 & 3274 & 2738297 & 13059358 \\
\hline 2018 & 609082 & 72472 & 4671 & 2200541 & 10448738 \\
\hline Ort. & 351742,333 & 55558,556 & 4612,000 & 1487885,778 & 3936985,333 \\
\hline YIllar & ÇSb6 & ÇSb7 & ÇSb8 & ÇSb9 & \\
\hline 2010 & 668535 & 0 & 156919 & 156533 & \\
\hline 2011 & 725189 & 0 & 47474 & 47439 & \\
\hline 2012 & 617789 & 4100 & 31040 & 35100 & \\
\hline 2013 & 350926 & 252200 & 77259 & 328200 & \\
\hline 2014 & 969379 & 149600 & 59019 & 280600 & \\
\hline 2015 & 1330114 & 46600 & 32715 & 78800 & \\
\hline 2016 & 1168362 & 7170 & 102072 & 109242 & \\
\hline 2017 & 1636313 & 34340 & 68360 & 102700 & \\
\hline 2018 & 1291157 & 8760 & 46280 & 55040 & \\
\hline Ort. & 973084,889 & 55863,333 & 69015,333 & 132628,222 & \\
\hline
\end{tabular}

Çizelge 3. SSB kapsamında yer alan kriterler bakımından 2010-2018 yıllarına ait veri seti

\begin{tabular}{|c|c|c|c|c|c|c|c|}
\hline Yıllar & SSb1 & SSb2 & SSb3 & SSb4 & SSb5 & SSb6 & SSb7 \\
\hline 2010 & 414 & 112 & 7,7 & 40 & 38 & 18 & 18 \\
\hline 2011 & 418 & 116 & 12,9 & 33 & 15 & 19 & 27 \\
\hline 2012 & 436 & 140 & 7,2 & 23 & 16 & 20 & 46 \\
\hline 2013 & 464 & 165 & 9,7 & 30 & 14 & 20 & 32 \\
\hline 2014 & 432 & 177 & 23,8 & 13 & 6 & 22 & 36 \\
\hline 2015 & 421 & 173 & 20,0 & 25 & 18 & 22 & 33 \\
\hline 2016 & 366 & 157 & 25,0 & 12 & 6 & 22 & 32 \\
\hline 2017 & 344 & 150 & 21,2 & 16 & 14 & 21 & 38 \\
\hline 2018 & 366 & 166 & 9,2 & 17 & 8 & 21 & 44 \\
\hline Ort. & 406,778 & 150,667 & 15,189 & 23,222 & 15,000 & 20,556 & 34,000 \\
\hline Yllar & SSb8 & SSb9 & SSb10 & SSb11 & SSb12 & SSb13 & SSb14 \\
\hline 2010 & 22 & 8213 & 27 & 0 & 0,0 & 12,40 & 93,30 \\
\hline 2011 & 25 & 8573 & 29 & 7 & 15,9 & 6,20 & 55,80 \\
\hline 2012 & 33 & 9443 & 33 & 8 & 16,1 & 0,00 & 0,00 \\
\hline 2013 & 20 & 12841 & 43 & 3 & 4,4 & 0,00 & 0,00 \\
\hline 2014 & 0 & 6720 & 26 & 1 & 1,8 & 5,95 & 73,37 \\
\hline 2015 & 0 & 6889 & 28 & 0 & 0,0 & 6,04 & 66,43 \\
\hline 2016 & 20 & 7491 & 36 & 0 & 0,0 & 2,17 & 195,74 \\
\hline 2017 & 20 & 6615 & 34 & 0 & 0,0 & 2,29 & 38,87 \\
\hline 2018 & 33 & 8657 & 43 & 4 & 6,0 & 8,82 & 156,56 \\
\hline Ort. & 19,222 & 8382,444 & 33,222 & 2,556 & 4,907 & 4,874 & 75,563 \\
\hline
\end{tabular}


Çizelge 4. ESB kapsamında yer alan kriterler bakımından 2010-2018 yıllarına ait veri seti

\begin{tabular}{|c|c|c|c|c|c|}
\hline Yıllar & ESb1 & ESb2 & ESb3 & ESb4 & ESb5 \\
\hline 2010 & 2,66 & 716903,1 & 428354752 & 7861984 & -25664536 \\
\hline 2011 & 1,35 & 365055,3 & 559970769 & 58925086 & -213336416 \\
\hline 2012 & 1,64 & 631756460,7 & 801981352 & -29343885 & 81115772 \\
\hline 2013 & 1,20 & 462260915,1 & 771028564 & -48931219 & -127081836 \\
\hline 2014 & 1,28 & 493078239,0 & 1124671014 & -75285310 & -321251586 \\
\hline 2015 & 0,95 & 365956579,8 & 1802888608 & 140444576 & -351005560 \\
\hline 2016 & 0,85 & 327434528,7 & 1420842034 & 63533848 & -548673970 \\
\hline 2017 & 0,91 & 350547653,7 & 1855097831 & -50089913 & -507197153 \\
\hline 2018 & 0,63 & 242686755,9 & 2215717988 & -45495731 & -1556396550 \\
\hline Ort. & 1,274 & 319422565 & 1220061434 & 2402159 & -396610203 \\
\hline Yllar & $\mathbf{E S b 6}$ & $\mathbf{E S b 7}$ & $\mathbf{E S b 8}$ & $\mathbf{E S b 9}$ & \\
\hline 2010 & 1910908243 & 0,0184 & $-0,0340$ & $-0,0134$ & \\
\hline 2011 & 2229212046 & 0,1052 & $-0,4065$ & $-0,0957$ & \\
\hline 2012 & 2823550025 & $-0,0366$ & 0,0861 & 0,0287 & \\
\hline 2013 & 3201382644 & $-0,0635$ & $-0,1534$ & $-0,0397$ & \\
\hline 2014 & 3244110714 & $-0,0669$ & $-0,6323$ & $-0,0990$ & \\
\hline 2015 & 5330857302 & 0,0779 & $-0,2147$ & $-0,0658$ & \\
\hline 2016 & 5044551542 & 0,0447 & $-0,4987$ & $-0,1088$ & \\
\hline 2017 & 5879213602 & $-0,0270$ & $-0,2714$ & $-0,0863$ & \\
\hline 2018 & 5704568702 & $-0,0205$ & $-3,3793$ & $-0,2728$ & \\
\hline Ort. & 3929817202 & 0,004 & $-0,612$ & $-0,084$ & \\
\hline
\end{tabular}

\section{BULGULAR}

Bu bölümde öncelikle, CRITIC-EDAS bütünleşik yöntemi ile firmanın kurumsal sürdürülebilirlik analizi gerçekleştirilmiş ve sonuçlar Bölüm 4.1'de tartışılmıştır. Sonrasında Bölüm 4.2'de kriterin ağırlıkları farklı objektif ağırlık yöntemleri ile hesaplanarak, CRITIC-EDAS bütünleşik yöntemi ile kıyaslanmış ve yöntemler arasında anlamlı bir fark olup olmadığı ortaya konmuştur.

\subsection{CRITIC-EDAS Bütünleşik Yaklaşımından Elde Edilen Sonuçlar}

Çizelge 2, 3 ve 4 kurumsal sürdürülebilirlik performans boyutlarını oluşturan kriterlere ait veri seti olup, aynı zamanda ÇKKV analizlerinde kullanılacak başlangıç karar matrisini oluşturan yapıları da göstermektedir. Çalışmada her bir boyut hem ayrı ayrı hem de birlikte ele alınarak firmanın belirtilen yıllar bazındaki sürdürülebilirlik performansı analiz edilmiştir.
EDAS yönteminin uygulanabilmesi için yöntemin girdisi olarak kriter ağırlıklarının belirlenmesi gereklidir. $\mathrm{Bu}$ doğrultuda öncelikle çevresel, sosyal ve ekonomik boyut altında yer alan 32 kriterin önem ağırlıkları CRITIC yöntemiyle belirlenmiştir. $\mathrm{Bu}$ amaçla enerji firmasının belirtilen kriterlere ilişkin veri setleri (Çizelge 2, 3, ve 4) kullanılarak, CRITIC yöntemiyle hesaplanan ağırlıklar Çizelge 5'de gösterilmiştir.

Çevresel sürdürülebilirlik boyutunda yer alan kriterlere ait ağırlıklar incelendiğinde, ağırlık değerlerinin birbirine yakın değerler aldığı ve aşırı büyük ağırlık değeri oluşmadığı görülmektedir. Sosyal sürdürülebilirlik boyutunda ise "SSb11" ile ifade edilen "araç kaza sayısı" ve "SSb12" ile ifade edilen "toplam araç kaza oranı" kriterlerinin daha yüksek ağırlık değerine sahip olduğu, bunun nedeni, Çizelge 5'de görüleceği üzere, bu kriterlerin yıllara göre değerlerinin daha yüksek farklılık göstermeleridir. Aynı durum, ekonomik sürdürülebilirlik boyutunda yer alan ve "ESb6" ile ifade edilen "toplam varlıklar" kriteri için de geçerlidir. 
Çizelge 5. CRITIC yöntemine göre elde edilen kriter ağırlıkları

\begin{tabular}{|c|c|c|c|c|c|c|c|}
\hline \multicolumn{2}{|c|}{ ÇSB } & \multicolumn{2}{c|}{ SSB } & \multicolumn{2}{c|}{ ESB } \\
\hline ÇSbj & A ğırlık & SSbj & Ağırlık & SSbj & A ğılık & ESbj & Ağırlık \\
\hline ÇSb1 & 0,03014 & SSb1 & 0,02486 & SSb8 & 0,03630 & ESb1 & 0,02683 \\
\hline CSSb2 & 0,03415 & SSb2 & 0,03476 & SSb9 & 0,02504 & ESb2 & 0,02853 \\
\hline ÇSb3 & 0,02442 & SSb3 & 0,03541 & SSb10 & 0,03650 & ESb3 & 0,03854 \\
\hline ÇSb4 & 0,02630 & SSb4 & 0,02965 & SSb11 & 0,04150 & ESb4 & 0,03134 \\
\hline CSSb5 & 0,03402 & SSb5 & 0,02752 & SSb12 & 0,04299 & ESb5 & 0,02363 \\
\hline ÇSb6 & 0,02597 & SSb6 & 0,03633 & SSb13 & 0,02844 & ESb6 & 0,04199 \\
\hline ÇSb7 & 0,02921 & SSb7 & 0,02928 & SSb14 & 0,02618 & ESb7 & 0,03632 \\
\hline CSSb8 & 0,02901 & & & & & ESb8 & 0,02536 \\
\hline ÇSb9 & 0,03745 & & & & & ESb9 & 0,02202 \\
\hline Toplam & $\mathbf{0 , 2 7 0 6 8}$ & Toplam & & & $\mathbf{0 , 4 5 4 7 6}$ & Toplam & $\mathbf{0 , 2 7 4 5 6}$ \\
\hline
\end{tabular}

Kriterlere ait ağırlıkların elde edilmesinden sonra bir sonraki adım, EDAS yönteminin kullanılması ile yıllar içindeki sürdürülebilirlik durumunun değerlendirilmesidir. Öncelikle bu yöntemin ilk üç adımına yönelik işlemler için Çizelge 2, 3 ve 4 matrisleri birleştirilerek işlemler yapılmıştır. Çizelge 6'da, yöntemde adım 3'e karşılık gelen ortalama çözüm değerleri verilmiştir. $\mathrm{Bu}$ işlemi takiben, adım 4'de verilmiş olan eşitlikler kullanılarak, $P D A_{i j}$ ve $N D A_{i j}$ değerleri hesaplanmıştır. Sonrasında, adım 5, 6 ve 7'de işlemlerin kullanılmasıyla Çizelge 7'deki nihai sonuçlar verilmiştir.
Çizelge 7'den, firmanın 2015 y1lında en iyi kurumsal sürdürülebilirlik performansını, 2014 y1lında en kötü kurumsal sürdürülebilirlik performansını ortaya koymuş olduğu görülmektedir. Sosyal, çevresel ve ekonomik sürdürülebilirlik boyutları ayrı olarak ele alınıp analiz edildiğinde, Çizelge 8 'deki veriler elde edilmiştir. Çizelge 8'de yer alan her bir sürdürülebilirlik boyutuna ait verilerin, daha iyi değerlendirilebilmesi amaciyla Şekil 1'de yıllara göre elde edilen ağırlıkların grafiği verilmiştir.

Çizelge 6. Tüm alt boyutların birlikte ele alınmasıyla elde edilen ortalama çözüm $(A V)$

\begin{tabular}{|c|c|c|c|c|c|c|c|c|}
\hline Yıllar & ÇSb1 & ÇSb2 & ÇSb3 & ÇSb4 & ÇSb5 & ÇSb6 & ÇSb7 & ÇSb8 \\
\hline 2010 & 0,908 & 0,709 & $-0,639$ & 0,068 & 0,967 & 0,313 & $-1,000$ & $-1,274$ \\
\hline 2011 & $-0,024$ & 0,721 & $-0,072$ & 0,045 & 0,969 & 0,255 & $-1,000$ & 0,312 \\
\hline 2012 & 0,075 & 0,640 & 0,330 & 0,174 & 0,969 & 0,365 & $-0,927$ & 0,550 \\
\hline 2013 & 0,653 & 0,544 & 0,239 & 0,701 & 0,987 & 0,639 & 3,515 & $-0,119$ \\
\hline 2014 & 0,843 & $-0,454$ & $-0,351$ & 0,611 & 0,917 & 0,004 & 1,678 & 0,145 \\
\hline 2015 & $-0,410$ & $-0,861$ & 0,727 & 0,208 & 0,817 & $-0,367$ & $-0,166$ & 0,526 \\
\hline 2016 & $-0,202$ & $-1,083$ & 0,042 & $-0,488$ & $-1,654$ & $-0,201$ & $-0,872$ & $-0,479$ \\
\hline 2017 & $-1,111$ & 0,088 & $-0,290$ & $-0,840$ & $-2,317$ & $-0,682$ & $-0,385$ & 0,009 \\
\hline 2018 & $-0,732$ & $-0,304$ & 0,013 & $-0,479$ & $-1,654$ & $-0,327$ & $-0,843$ & 0,329 \\
\hline Ylllar & ÇSb9 & $\mathbf{S S b 1}$ & $\mathbf{S S b 2}$ & $\mathbf{S S b 3}$ & $\mathbf{S S b 4}$ & $\mathbf{S S b 5}$ & $\mathbf{S S b 6}$ & $\mathbf{S S b 7}$ \\
\hline 2010 & $-0,180$ & 0,018 & $-0,257$ & 0,493 & 0,722 & 1,533 & $-0,124$ & $-0,471$ \\
\hline 2011 & 0,642 & 0,028 & $-0,230$ & 0,151 & 0,421 & 0,000 & $-0,076$ & $-0,206$ \\
\hline 2012 & 0,735 & 0,072 & $-0,071$ & 0,526 & $-0,010$ & 0,067 & $-0,027$ & 0,353 \\
\hline 2013 & $-1,475$ & 0,141 & 0,095 & 0,361 & 0,292 & $-0,067$ & $-0,027$ & $-0,059$ \\
\hline 2014 & $-1,116$ & 0,062 & 0,175 & $-0,567$ & $-0,440$ & $-0,600$ & 0,070 & 0,059 \\
\hline 2015 & 0,406 & 0,035 & 0,148 & $-0,317$ & 0,077 & 0,200 & 0,070 & $-0,029$ \\
\hline 2016 & 0,176 & $-0,100$ & 0,042 & $-0,646$ & $-0,483$ & $-0,600$ & 0,070 & $-0,059$ \\
\hline 2017 & 0,226 & $-0,154$ & $-0,004$ & $-0,396$ & $-0,311$ & $-0,067$ & 0,022 & 0,118 \\
\hline 2018 & 0,585 & $-0,100$ & 0,102 & 0,394 & $-0,268$ & $-0,467$ & 0,022 & 0,294 \\
\hline
\end{tabular}


Çizelge 6. (devam)

\begin{tabular}{|c|c|c|c|c|c|c|c|c|}
\hline Yıllar & SSb8 & SSb9 & SSb10 & SSb11 & SSb12 & SSb13 & SSb14 & ESb1 \\
\hline 2010 & 0,145 & $-0,020$ & $-0,187$ & 1,000 & 1,000 & $-1,544$ & $-0,235$ & 1,087 \\
\hline 2011 & 0,301 & 0,023 & $-0,127$ & $-1,739$ & $-2,240$ & $-0,272$ & 0,262 & 0,059 \\
\hline 2012 & 0,717 & 0,127 & $-0,007$ & $-2,130$ & $-2,281$ & 1,000 & 1,000 & 0,287 \\
\hline 2013 & 0,040 & 0,532 & 0,294 & $-0,174$ & 0,111 & 1,000 & 1,000 & $-0,058$ \\
\hline 2014 & $-1,000$ & $-0,198$ & $-0,217$ & 0,609 & 0,633 & $-0,221$ & 0,029 & 0,004 \\
\hline 2015 & $-1,000$ & $-0,178$ & $-0,157$ & 1,000 & 1,000 & $-0,239$ & 0,121 & $-0,255$ \\
\hline 2016 & 0,040 & $-0,106$ & 0,084 & 1,000 & 1,000 & 0,555 & $-1,590$ & $-0,333$ \\
\hline 2017 & 0,040 & $-0,211$ & 0,023 & 1,000 & 1,000 & 0,530 & 0,486 & $-0,286$ \\
\hline 2018 & 0,717 & 0,033 & 0,294 & $-0,565$ & $-0,223$ & $-0,809$ & $-1,072$ & $-0,506$ \\
\hline Yıllar & $\mathbf{E S b 2}$ & $\mathbf{E S b 3}$ & $\mathbf{E S b 4}$ & $\mathbf{E S b 5}$ & $\mathbf{E S b 6}$ & $\mathbf{E S b 7}$ & $\mathbf{E S b 8}$ & $\mathbf{E S b 9}$ \\
\hline 2010 & $-0,998$ & $-0,649$ & 2,273 & $-0,935$ & $-0,514$ & 4,215 & $-0,944$ & $-0,840$ \\
\hline 2011 & $-0,999$ & $-0,541$ & 23,530 & $-0,462$ & $-0,433$ & 28,902 & $-0,335$ & 0,144 \\
\hline 2012 & 0,978 & $-0,343$ & $-13,216$ & $-1,205$ & $-0,282$ & $-11,397$ & $-1,141$ & $-1,343$ \\
\hline 2013 & 0,447 & $-0,368$ & $-21,370$ & $-0,680$ & $-0,185$ & $-19,033$ & $-0,749$ & $-0,525$ \\
\hline 2014 & 0,544 & $-0,078$ & $-32,341$ & $-0,190$ & $-0,174$ & $-20,022$ & 0,034 & 0,184 \\
\hline 2015 & 0,146 & 0,478 & 57,466 & $-0,115$ & 0,357 & 21,136 & $-0,649$ & $-0,213$ \\
\hline 2016 & 0,025 & 0,165 & 25,449 & 0,383 & 0,284 & 11,706 & $-0,185$ & 0,300 \\
\hline 2017 & 0,097 & 0,520 & $-21,852$ & 0,279 & 0,496 & $-8,673$ & $-0,556$ & 0,031 \\
\hline 2018 & $-0,240$ & 0,816 & $-19,940$ & 2,924 & 0,452 & $-6,835$ & 4,526 & 2,262 \\
\hline
\end{tabular}

Firmanın 2016 yılında bazı üretim tesisleri için, ISO 14001:2015 Çevre Yönetim Sistemleri belgesini aldığı bilinmektedir. Çevre alanında yapılan bunun gibi yatırımların, 2017 yılından itibaren olumlu anlamda geri dönüş sağladığ görülmektedir. Sosyal sürdürülebilirlik performansının özellikle 2013 yılından sonra çok büyük bir değişime sahip olmadığını; 2010 yılında firmanın en iyi sosyal sürdürülebilirlik performansını elde edilirken, 2011 yılı ise en kötü sosyal sürdürülebilirlik performansını elde ettiği görülmektedir. Ekonomik sürdürülebilirlik açısından firmanın 2011 yılında iyi bir seviyeden düşüş eğilimine geçtiği ve yeniden toparlanma sağladığı 2014 yılına kadar ciddi bir düşüş yaşadığı görülmektedir.

Çizelge 7. Tüm boyutların birlikte ele alınmasıyla elde edilen nihai sonuçlar ve sıralama sonucu

\begin{tabular}{|c|c|c|c|c|c|c|}
\hline Yllar & $\boldsymbol{S P}_{\boldsymbol{i}}$ & $\boldsymbol{S N}_{\boldsymbol{i}}$ & $\boldsymbol{N S P}_{\boldsymbol{i}}$ & $\boldsymbol{N S}_{\boldsymbol{i}}$ & $\boldsymbol{A S}_{\boldsymbol{i}}$ & $\boldsymbol{S i r a}_{\mathbf{~}}$ \\
\hline 2010 & 0,5192 & 0,3127 & 0,1860 & 0,8377 & 0,5118 & 4 \\
\hline 2011 & 1,9272 & 0,3163 & 0,6904 & 0,8358 & 0,7631 & 2 \\
\hline 2012 & 0,2747 & 1,1576 & 0,0984 & 0,3991 & 0,2487 & 6 \\
\hline 2013 & 0,3413 & 1,5016 & 0,1223 & 0,2205 & 0,1714 & 8 \\
\hline 2014 & 0,2116 & 1,9264 & 0,0758 & 0,0000 & 0,0379 & 9 \\
\hline 2015 & 2,7915 & 0,1522 & 1,0000 & 0,9210 & 0,9605 & 1 \\
\hline 2016 & 1,3737 & 0,2726 & 0,4921 & 0,8585 & 0,6753 & 3 \\
\hline 2017 & 0,1815 & 1,2263 & 0,0650 & 0,3634 & 0,2142 & 7 \\
\hline 2018 & 0,3803 & 1,1353 & 0,1362 & 0,4107 & 0,2735 & 5 \\
\hline
\end{tabular}

Çizelge 8. Her bir boyut açısından elde edilen performans sıralama sonuçları

\begin{tabular}{|c|c|c|c|c|c|c|}
\hline & \multicolumn{2}{|c|}{ ÇSB } & \multicolumn{2}{c|}{ SSB } & \multicolumn{2}{c|}{ ESB } \\
\hline Yıllar & $\boldsymbol{A S}_{\boldsymbol{i}}$ & Sira & $\boldsymbol{A} \boldsymbol{S}_{\boldsymbol{i}}$ & Sira & $\boldsymbol{A \boldsymbol { S } _ { \boldsymbol { i } }}$ & Sira \\
\hline 2010 & 0,3739 & 6 & 0,9128 & 1 & 0,5041 & 4 \\
\hline 2011 & 0,6233 & 3 & 0,1134 & 9 & 0,8170 & 2 \\
\hline 2012 & 0,7018 & 2 & 0,2089 & 8 & 0,2374 & 6 \\
\hline
\end{tabular}


Çizelge 8. (devam)

\begin{tabular}{|c|c|c|c|c|c|c|}
\hline & \multicolumn{2}{|c|}{ CSB } & \multicolumn{2}{c|}{ SSB } & \multicolumn{2}{c|}{ ESB } \\
\hline Yıllar & $\boldsymbol{A} \boldsymbol{S}_{\boldsymbol{i}}$ & Sıra & $\boldsymbol{A S}_{\boldsymbol{i}}$ & Sıra & $\boldsymbol{A S}_{\boldsymbol{i}}$ & Sira \\
\hline 2013 & 0,7469 & 1 & 0,6551 & 2 & 0,0924 & 8 \\
\hline 2014 & 0,5165 & 5 & 0,4167 & 7 & 0,0050 & 9 \\
\hline 2015 & 0,5167 & 4 & 0,6062 & 4 & 0,9905 & 1 \\
\hline 2016 & 0,0332 & 9 & 0,5523 & 6 & 0,7376 & 3 \\
\hline 2017 & 0,0341 & 8 & 0,6120 & 3 & 0,2218 & 7 \\
\hline 2018 & 0,1881 & 7 & 0,5639 & 5 & 0,3052 & 5 \\
\hline
\end{tabular}

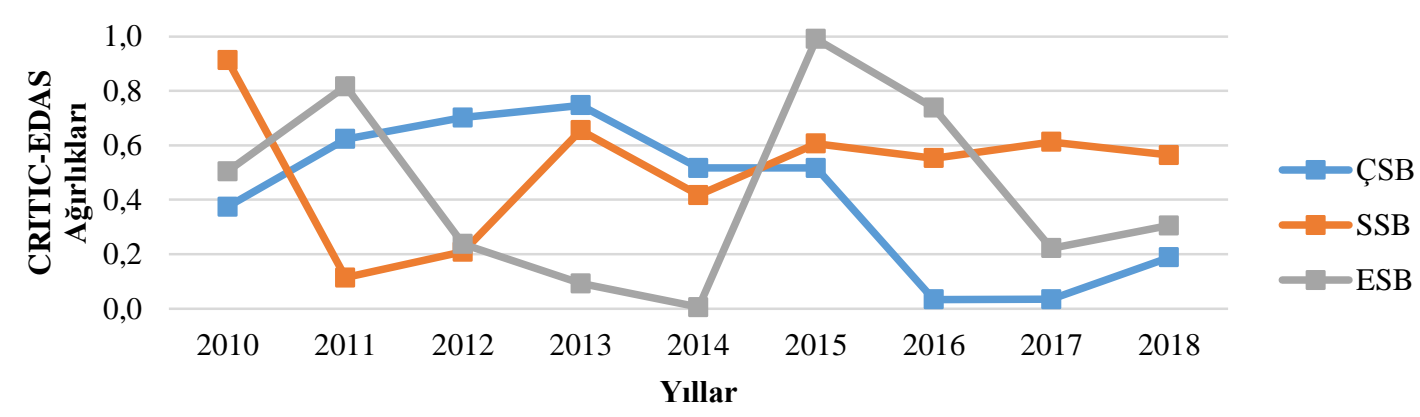

Şekil 1. 2010-2018 yılları itibariyle enerji firmasının her bir boyut açısından performans ölçümü

2011 yılındaki küresel ekonomik kriz ile bağlantı piyasa koşullarının ve firmanın 2012 yılında yaptığı yeni yatırımların, firmayı zorlamış ve ekonomik sürdürülebilirlikteki düşüş etkisini tetiklemiş olabileceği düşünülmektedir.

2015 yılında en yüksek seviyeye ulaşan ekonomik sürdürülebilirlik performansı, bu yıl sonrasında tekrar düşüşe geçmiş ve ardında 2017 itibariyle yükselişe geçmiştir. Firmanın çevresel sürdürülebilirlik ve ekonomik sürdürülebilirlik açısından çok istikrarlı bir durum sergileyemeyişi, genel kurumsal sürdürülebilirlik performansına da yansımaktadır. Ancak, her iki sürdürülebilirlik alt boyutunda 2018 yılında yükseliş olması, firma açısından olumlu bir durum olarak ortaya çıkmaktadır.

\subsection{Farklı Objektif Yöntemleri ile Kıyaslama \\ A ğırlıklandırma}

Farklı ağırlıklandırma yöntemlerinin, sonuç üzerindeki etkisini görebilmek amacıyla, önerilen CRITIC-EDAS bütünleşik yönteminden elde edilen performans sıralama sonuçları, farklı objektif ağırlıklandırma yöntemleri ile EDAS yönteminin bütünleştirilmesiyle elde edilen diğer bütünleşik yöntemlerle karşılaştırılmıştır.

Farklı bütünleşik yöntemler kullanılarak enerji firmasının yıllar itibariyle kurumsal sürdürülebilirlik performans sıralamasına ait sonuçları Çizelge 9'da gösterilmiştir.

Farklı ağırlıklandırma yöntemleri ile elde edilen sonuçlar arasında anlamlı bir farkın olup olmadığını tespit etmek amacıyla Spearman korelasyon testi kullanılmış ve elde edilen sonuçlar Çizelge 10'da verilmiştir.

Çalışmada önerilen CRITIC-EDAS bütünleşik yaklaşımı ile diğer ağırlıklandırma yöntemleri ile oluşturulan bütünleşik yaklaşımlar arasında yüksek benzerlik olduğu Çizelge 10'da görülmektedir.

Sonuç olarak, farklı ağırlıklandırma yöntemlerini mevcut firmanın kurumsal sürdürülebilirlik analiz sonuçlarında anlamlı bir fark yaratmamıştır. 
Çizelge 9. Tüm boyutların birlikte ele alınmasıyla elde edilen farklı bütünleşik yaklaşımlara göre performans sıralama sonuçları

\begin{tabular}{|c|c|c|c|c|c|c|c|c|}
\hline & \multicolumn{2}{|c|}{ CRITIC-EDAS } & \multicolumn{2}{c|}{ MW-EDAS } & \multicolumn{2}{c|}{ ENTROPİ-EDAS } & \multicolumn{2}{c|}{ CV-EDAS } \\
\hline Yıllar & $\boldsymbol{A S}_{\boldsymbol{i}}$ & Sıra & $\boldsymbol{A S}_{\boldsymbol{i}}$ & Sıra & $\boldsymbol{A} \boldsymbol{S}_{\boldsymbol{i}}$ & $\boldsymbol{S I r a}$ & $\boldsymbol{A} \boldsymbol{S}_{\boldsymbol{i}}$ & Sıra \\
\hline $\mathbf{2 0 1 0}$ & 0,5118 & 4 & 0,4977 & 4 & 0,5175 & 4 & 0,2748 & 4 \\
\hline $\mathbf{2 0 1 1}$ & 0,7631 & 2 & 0,7587 & 2 & 0,7708 & 2 & 0,3988 & 2 \\
\hline $\mathbf{2 0 1 2}$ & 0,2487 & 6 & 0,2563 & 6 & 0,2563 & 5 & 0,4541 & 5 \\
\hline $\mathbf{2 0 1 3}$ & 0,1714 & 8 & 0,1811 & 8 & 0,2065 & 7 & 0,8904 & 8 \\
\hline $\mathbf{2 0 1 4}$ & 0,0379 & 9 & 0,0389 & 9 & 0,0417 & 9 & 0,6203 & 9 \\
\hline $\mathbf{2 0 1 5}$ & 0,9605 & 1 & 0,9573 & 1 & 0,9697 & 1 & 0,4287 & 1 \\
\hline $\mathbf{2 0 1 6}$ & 0,6753 & 3 & 0,6650 & 3 & 0,6725 & 3 & 0,0077 & 3 \\
\hline $\mathbf{2 0 1 7}$ & 0,2142 & 7 & 0,2003 & 7 & 0,2003 & 8 & 0,0117 & 7 \\
\hline $\mathbf{2 0 1 8}$ & 0,2735 & 5 & 0,2760 & 5 & 0,2386 & 6 & 0,0765 & 6 \\
\hline
\end{tabular}

Çizelge 10. Bütünleşik yaklaşımların sıralama sonuçlarının Spearman korelasyon katsayısı $\left(r_{s}\right)$

\begin{tabular}{|l|c|c|c|c|}
\hline & CRITIC-EDAS & MW-EDAS & ENTROPI-EDAS & CV-EDAS \\
\hline CRITIC-EDAS & 1 & 1,000 & 0,967 & 0,983 \\
\hline MW-EDAS & - & 1 & 0,967 & 0,983 \\
\hline ENTROPY-EDAS & - & - & 1 & 0,983 \\
\hline CV-EDAS & - & - & - & 1 \\
\hline
\end{tabular}

\section{SONUÇ}

Enerji firmalarının gerek ülke ekonomisi gerekse stratejik önemleri dikkate alındığında, kurumsal sürdürülebilirlik farkındalığı ve uygulamaları açısından öncü firmalar arasında yer alması beklenmektedir. Ancak, BISST'de yer alan enerji firmaları incelendiğinde, dokuz enerji firması içerisinde üç tanesinin sürdürülebilirlik raporu yayınladığı görülmektedir. Bununla birlikte sürdürülebilirlik raporu yayınlayan firmaların önemli bir bölümünün istikrarlı bir şekilde her yıl için aynı göstergeleri sunmadığı ortaya çıkmıştır. Sektörlere göre göstergelerin belirlenip, firmaların sürdürülebilirlik raporlarında bu verileri bulundurmaları, hem firma bazında değerlendirilme yapılması, hem de sektördeki firmaların birbirleriyle kiyaslanarak değerlendirilmeleri açısından bir zorunluluktur.

$\mathrm{Bu}$ çalışmada, BİST'de işlem gören bir enerji firmasının 2010-2018 yılları arasında kurumsal sürdürülebilirlik performans değerlendirme analizi için ÇKKV yöntemlerinden CRITIC-EDAS bütünleşik yaklaşımı önerilmiştir. $\mathrm{Bu}$ amaçla, öncelikle ilgili enerji firmasının sürdürülebilirlik raporlarında yer alan ekonomik, çevresel ve sosyal sürdürülebilirlik boyutlarına ait göstergeler dikkate alınarak kriterler ortaya konmuştur. Ekonomik göstergelerin ortaya konmasında, ilgili firmaya ait faaliyet raporları da kullanılmıştır. Belirlenen göstergelerin ağırlıkları, uzman görüşlerine ihtiyaç duyulmaksızın, CRITIC yöntemiyle objektif olarak hesaplanmıştır. Sonrasında, EDAS yönteminin uygulanması ile elde edilen veriler 1şı̆̆ında; firmanın kurumsal sürdürülebilirlik performansının çok istikrarlı bir durum sergilemediği ancak, 2018 yılında çevresel sürdürülebilirlik ve ekonomik sürdürülebilirlik boyutlarında yükseliş olduğu görülmüştür. Ayrıca çalışmada son olarak, farklı objektif ağırlıklandırma yöntemleri kullanılmış ve bu yöntemlerden elde edilen ağırlıklar çalışmada önerilen yaklaşımda olduğu gibi EDAS yöntemiyle entegre edilerek farklı bütünleşik yaklaşımlar elde edilmiştir.

Böylece, bu yaklaşımlara göre yıllar bazındaki performans skorları elde edilerek yılların sıralamaları belirlenmiştir. Farklı bütünleşik yaklaşımlardan elde edilen sonuçların birbirlerine göre kıyaslaması için Spearman korelasyon testi kullanılmış ve sıralama sonuçları arasında hemen hemen fark görülmediği tespit edilmiştir. 


\section{KAYNAKLAR}

1. Düzer, M., Önce, S., 2017. Kurumsal Sürdürülebilirlik Raporlaması ve Finansal Performans: BISST'te İşlem Gören Şirketler için Karşıllaştırmalı Bir Analiz. Bilecik Şeyh Edebali Üniversitesi Sosyal Bilimler Enstitüsü Dergisi, 2(2), 637-648.

2. Öner, Ş., Ağca, A., 2018. İşletmelerin Risk Gruplarına Göre Çevresel Sürdürülebilirlik Uygulamaları: BIST 100 Endeksinde Bir Uygulama. İnsan ve Toplum Bilimleri Araştırmaları Dergisi, 7(1), 77-89.

3. Once, S., Onay A., Yeşilçelebi, G., 2015. Corporate Sustainability Reporting and Situation in Turkey. Journal of Economics, Finance and Accounting, 2(2), 230-252.

4. Gürül, B., 2016. Kurumsal Sürdürülebilirlik Yaklaşımı-Bir Örnek. International Conference on Eurasian Economies, August 29-31, Kaposvar-Hungar.

5. Gücenme, U., Aytaç, A., 2016. Kurumsal Sürdürülebilirlik Açısından Entegre Raporlamanın Önemi ve BIST Uygulamaları. Muhasebe ve Finansman Dergisi, 72, 51-66.

6. Alp, İ., Öztel, A., Köse, M.S., 2015. Entropi Tabanlı MAUT Yöntemi ile Kurumsal Sürdürülebilirlik Performansı Ölçümü: Bir Vaka Çalışması. Ekonomik ve Sosyal Araştırmalar Dergisi, 11(2), 65-81.

7. Ergüden, E., Çatlıŏlu, E., 2016. Sustainability Reporting Practiceses in Energy Companies with TOPSIS Method. Muhasebe ve Finansman Dergisi, 71, 201-222.

8. Aras, G., Tezcan, N., Furtuna, O.K., Kazak, E.H., 2017. Corporate Sustainability Measurement Based on Entropy Weight and Topsis: A Turkish Banking Case Study. Meditari Accountancy Research, 25(3), 391-413.

9. Ömürbek, V., Aksoy, E., Akçakanat, Ö., 2017. Bankaların Sürdürülebilirlik Performansının ARAS, MOOSRA ve COPRAS Yöntemleri ile Değerlendirilmesi. Süleyman Demirel Üniversitesi Vizyoner Dergisi, 8(19), 14-32.

10. Küçükbay, F., Sürücü, E., 2017. Corporate Sustainability Performance Measurement Based on a New Multicriteria Sorting Method.
Corporate Social Responsibility and Environmental Management, 26, 664-680.

11. Ersoy, N., 2018. Entropy Tabanlı Bütünleşik ÇKKV Yaklaşımı ile Kurumsal Sürdürülebilirlik Performans Ölçümü. Ege Akademik Bakış, 18(3), 367-385.

12. Öztel, A., Aydın, B., Köse, M.S., 2018. Entropi Tabanlı TOPSIS Yöntemiyle Enerji Sektöründe Kurumsal Sürdürülebilirlik Performansının Ölçümü: Akenerji Örneği. Gümüşhane Üniversitesi Sosyal Bilimler Enstitüsü Dergisi, 9(24).

13.Ecer, F., 2019. Özel Sermayeli Bankaların Kurumsal Sürdürülebilirlik Performanslarının Değerlendirilmesine Yönelik Çok Kriterli Bir Yaklaşım: Enropi- ARAS Bütünleşik Modeli. Eskişehir Osmangazi Üniversitesi İ̈BF Dergisi, 14(2), 364-390.

14. Korzeb, Z., Medina, R.S., 2019. Sustainability Performance. A Comparative Analysis in the Polish Banking Sector. Sustainability, 11(653), 1-16.

15. Stojcic, M., Zavadskas, E.K., Pamucar, D., Stevic, Z., Mardani, A., 2019. Application of MCDM Metods in Sustainability Engineering: A literature revirew 2008-2028. Symmetry, 11 (350), 1-24.

16. Wang, Y.M., Luo, Y., 2010. Integration of Correlations with Standard Deviations for Determining Attribute Weights in Multiple Attribute Decision Making. Mathematical and Computer Modelling, 51(1-2), 1-12.

17. Deng, H., Yeh, C.H., Willis, R.J., 2000. InterCompany Comparison Using Modified TOPSIS with Objective Weights. Computers \& Operations Research, 27, 963-973.

18. Diakoulaki, D., Mavrotas, G., Papayannakis, L. 1995. Determining Objective Weights in Multiple Criteria Problems: the CRITIC method. Computers \& Operations Research, 22(7), 763-770.

19. Wang, Y.M., 1998. Using the Method of Maximizing Deviations to Make Decision for Multi-indices. Systems Engineering and Electronics, 7(31), 24-26.

20. Ma, J., Fan, Z.P., Huang, L.H., 1999. A Subjective and Objective Integrated Approach to Determine Attribute Weights. European Journal of Operational Research, 112, 397-404. 
21. Keshavarz Ghorabaee, M., Zavadskas, E.K., Olfat, L., Turskis, Z., 2015. Multi-criteria Inventory Classification Using a New Method of Evaluation Based on Distance from Average Solution (EDAS). Informatica, 26(3), 435-451.

22. Keshavarz Ghorabaee, M., Zavadskas, E.K., Amiri, M., Turskis, Z., 2016. Extended EDAS Method for Fuzzy Multi-criteria Decisionmaking: an Application to Supplier Selection. International Journal of Computers Communications \& Control, 11(3), 358-371.

23. Ulutaş, A., 2017. Edas Yöntemi Kullanılarak Bir Tekstil Atölyesi için Dikiş Makinesi Seçimi, İşletme Araştırmaları Dergisi, 9(2), 169-83.

24. Juodagalvienė, B., Turskis, Z., Šaparauskas, J., Endriukaitytè, A., 2017. Integrated Multicriteria Evaluation of House's Plan Shape Based on the EDAS and SWARA Methods. Engineering Structures and Technologies, 9(3), 117-125.

25. Kahraman, C., Keshavarz Ghorabaee, M., Zavadskas, E.K., Cevik Onar, S., Yazdani, M., Oztaysi, B., 2017. Intuitionistic Fuzzy EDAS Method: An Application to Solid Waste Disposal Site Selection. Journal of Environmental Engineering and Landscape Management 25(1), 1-12.

26. Ecer, F., 2018. Third-party Logistics (3PLs) Provider Selection Via Fuzzy AHP and EDAS Integrated Model. Technological and Economic Development of Economy, 24(2), 615-634.

27. Karabasevic, D., Zavadskas, E.K., Stanujkic, D., Popovic, G., Brzakovic, M., 2018. An Approach to Personnel Selection in the IT Industry Based on the EDAS Method. Transformations in Business \& Economics, 44, 54-65.

28. Mathew, M., Sahu, S., 2018. Comparison of New Multi-criteria Decision Making Methods for Material Handling Equipment Selection. Management Science Letters, 8(3), 139-150.

29. Chatterjee, P., Banerjee, A., Mondal, S., Boral, S., Chakraborty, S., 2018. Development of a Hybrid Meta-Model for Material Selection Using Design of Experiments and Edas Method. Engineering Transactions, 66(2), 187-207.
30. Özbek, A., Engür, M., 2018. EDAS Yöntemi ile Lojistik Firma Web Sitelerinin Değerlendirilmesi. Selçuk Üniversitesi, Sosyal Bilimler Meslek Yüksekokulu Dergisi, 21(2), 417-429.

31. Kowal, B., Kostra, A., 2016. Sustainability Reporting in the Energy Sector. E3S Web of Conferences 10, SEED 00129 (2016). 
